\title{
INFANT BEHAVIOUR AND DEVELOPMENT IN HOOLOCK GIBBON (BUNOPITHECUS HOOLOCK HOOLOCK)
}

\author{
M. Farid Ahsan
}

Wildlife Research Group, Department of Anatomy, University of Cambridge, Cambridge CB2 3DY, United Kingdom Permanent address: Department of Zoology, University of Chittagong, Chittagong 4331, Bangladesh

\section{AbstRact}

Infant behaviour and development was recorded for Hoolock Gibbon (Bunopithecus hoolock hoolock) in nature during December 1988 to December 1990. The study was carried out at West Bhanugach Reserve Forest under Sylhet Forest Division of Bangladesh.

\author{
KEY WORDS \\ Bunopithecus hoolock hoolock, development, Hoolock \\ gibbon, infant behaviour
}

Hoolock Gibbon (Bunopithecus hoolock hoolock) is a monogamous, diurnal, arboreal and territorial small ape living in a small family group of one-mated adult pairs with up to four offspring inhabiting the tropical rain forest of northeastern parts of South Asia and northwestern parts of South East Asia (see Ahsan, 1994). It is patchily distributed in the mixed evergreen forests of northeast to southeast of Bangladesh (see Ahsan, 1984). Infant behaviour and its development was carefully noted while studying ecology and behaviour of the Hoolock Gibbon in Bangladesh.

Some important ecological factors like food, secured habitat and mate influence, group behaviour of primates in general and in turn infant behaviour and its development also to some extent depend upon group composition and behaviour. The relative importance of such factors may not be the same for all group members. For instance, the behavioural development of an infant depends upon the social oragnisation of the group and especially siblings play a dominant role in this regard; the density and patchiness of food supply (Crook \& Gartlan, 1966; Crook, 1972; Ditttus, 1975; Clutton-Brock \& Harvey, 1977a,b, 1978; Klein \& Klein, 1977; Struhsaker \& Leland, 1979; Gittins \& Raemaekers, 1980); and the provision of a secure environment to rear offspring (Gross-Custard et al., 1972; Crook et al., 1976).

This paper deals with infant behaviour and its development of Hoolock Gibbon in wild habitat (nature) of Bangladesh.

\section{Methods}

Hoolock Gibbons were studied at Lawachara $\left(24^{0} 32^{\prime} \mathrm{N} \& 9^{\circ} 49^{\prime} \mathrm{E}\right)$ of West Bhanugach Reserve Forest (now declared as Lawachara National Park) under Sylhet Forest Division of Bangladesh. Description of the study area is available in Ahsan (1994). The study was conducted between December 1988 and December 1990, when two groups (L1 \& L2, see Table 1) of gibbons were intensively monitored. Infant behaviour and its development were noted during scan samplings (Altmann, 1974). Besides two intensive study groups, data on the mentioned events were also noted in neighbouring groups. All records and experiences (both present and past) were jotted down.

\section{Results and Discussion}

Reports on infant behaviour and development in Hoolock Gibbons are very scanty. In December 1988 group L2 had a baby, who was born between September and November 1988, as estimated from the size, colour of the baby (infant) and its way of clinging to its mother's chest. The experiences of seeing the newborn infant of L1 (born between 15-25 September 1990) and other observations (see Ahsan, 1994) also supported this assumption. The discussion here is mostly based on the study of group L2 and the information that was supplemented by L1, but some occasional observations on other groups has also enriched this discussion.

Colour: The newly born baby of the Hoolock Gibbon is palegrey whitish-yellow or whitish-yellow, but the face, palms and soles are black. Within six months of birth, the coat colour becomes a bit brighter (yellowish). Then it gradually changes to yellowish-brown. At 12 months the coat colour turns to dark brown/black especially on the chest, belly and undersides of limbs, and the skin looks black, but the line along the vertebral column remains whitish-yellow. The colour gradually changes to black and at the age of 15 months, except for a pale yellow chest and a line along the spine, other parts are blackish, but a yellow tinge can still be noticed. Yellowish-white/goldenwhitish eyebrows are noticeable at this stage. The hand and feet are black. After 18 months, all parts are black except the line of the spine, which is yellowish-brown. At the age of 24 months, the coat colour is nearly completely black and silverywhite eyebrows are distinctly prominent.

Behavioural development: For the first two months after birth, it is hard to see the front of the baby since it mainly clings to its mother's chest and belly hair. In February 1989, I saw the front side of the baby of L2 group when the juvenile-II of the group was playing with her sibling infant (about 4-months old), who was sitting in its mother's lap during a resting bout of the mother. In June 1989, for the first time I observed the infant out of its mother's lap for a while, i.e., when the baby was six months of age. At the age of about 14 months (December 1989) the infant frequently ventured away from its mother's lap, playing acrobatically for short periods, moving 2-3m around its mother and occasionally eating small fruits (especially Ficus gibbosa).

In February (7.ii.1990) the infant was seen $2 \mathrm{~m}$ ahead of its mother, as the group was progressing towards a food source when it suddenly dropped to the ground from a height of about $10 \mathrm{~m}$. . Hearing the infant's cry/squeal and/or distress calls, all 
Table 1. Intensive study groups

\begin{tabular}{|c|c|c|c|c|c|c|c|}
\hline Group & & ul & & You & & & Total \\
\hline & & & Juv-II & Juv-I & Infant-II & Infant-I & \\
\hline Decemb & 19 & & & & & & \\
\hline L1 & 1 & 2 & - & - & - & - & 4 \\
\hline L2 & 1 & 1 & $1(F)$ & $1(\mathrm{~F})$ & - & 1 & 5 \\
\hline Decemb & 19 & & & & & & \\
\hline L1 & 1 & 1 & - & $1(\mathrm{M})$ & - & 1 & 4 \\
\hline L2 & 1 & 1 & $1(F)$ & $1(F)$ & 1 & - & 5 \\
\hline
\end{tabular}

members of the group L2 came forward curiously. However, the infant had already climbed up on a small tree and the mother came down to about $2 \mathrm{~m}$ above the ground and reached forward with her right hand to retrieve the infant. Within an hour of the incident the infant was once more moving freely in the trees and playing by itself.

In March 1990 (when about 17-months old), the infant was even more independent; wrestling and playing with juvenile-I and -II (females), but still was no farther than $3 \mathrm{~m}$ from the mother. In April, the infant (about 18-months) was first seen to groom its mother for a while, possibly because the father was already grooming her. In May, the infant spent even more time apart from the female independently, either following its mother, or ahead of her, but still being helped in crossing difficult tree gaps. Generally, the mother helped either with her hands, legs or took the infant in her lap, but other group members also occasionally helped by hand in those situations. In June the infant was even more confident in moving and feeding alone, following its mother or moving ahead, not more than $5 \mathrm{~m}$ during short group progression, and playing frequently with juvenilesI and II. In July (about 21-months of age) short leaps and jumps were noticed. In August (at about 22-months) it was more confident in leaping and jumping, and trying to cross difficult routes by searching for alternative easy routes. However, for swift and long travel during group progression the mother still carried the infant ventrally, frequently releasing the infant from her lap to rest, possibly because it was too heavy for her to carry for a long period. In December 1990 the infant (about 26-months) was performing all activities freely, but still suckling from time to time and spending the night with its mother.
Since then I have been told (S.M.D. Hossain \& M.S. Huda pers. comm.) that in April 1991, the infant, now considered a juvenile-I at 2.5 years (30-months) old, was doing all activities independently, but retreated to its mother when approached by humans or in case of potential danger; no suckling was observed. At the end of May 1991, the mother refused to accept the infant (about 31-months old) in her lap in such situations.

\section{REFERENCES}

Ahsan, M.F. (1984). Study of primates in Bangladesh: determination of population status and distribution of non-human primates in Bangladesh with emphasis on Rhesus monkey. Unpublished M. Phil. thesis. University of Dhaka, Dhaka.

Ahsan, M.F. (1994). Behavioural Ecology of the Hoolock Gibbon (Hylobates hoolock) in Bangladesh. Ph.D. Thesis. University of Cambridge, Cambridge (Unpublished).

Altmann, J. (1974). Observational study of behaviour: sampling methods. Behaviour 49: 222-267.

Clutton-Brock, T.H. and P.H. Harvey (1977a). Primate ecology and social organization. Journal of Zoology 183:1-39.

Clutton-Brock, T.H. and P.H. Harvey (1977b). Species differences in feeding and ranging behaviour in primates, pp.557-584. In: CluttonBrock, T.H. (Editor) Primate ecology: Studies of Feeding and Ranging Behaviour in Lemurs, Monkeys and Apes. Academic Press, London.

Clutton-Brock, T.H. and P.H. Harvey (1978). Mammals, resources and reproductive strategies. Nature 273: 191-195.

Crook, J.H. (1972). Sexual selection, dimorphism and social organization in the primates, pp.231-281. In: Campbell, B.C. (Editor) Sexual Selection and the Descent of Man. Adeline Press, Chicago.

Crook, J.H. and J.S. Gartlan (1966). Evolution of primate societies. Nature 210:1200-1203.

Crook, J.H., J.E. Ellis and J.D. Goss-Custard (1976). Mammalian social systems: structure and function. Animal Behaviour 24: 261-274. Dittus, W.P.J. (1975). Population dynamics of the toque monkey, Macaca sinica. pp.125-151. In: Tuttle, R.H. (Editor) Socioecology and Psychology of Primates. Mouton Press, The Hague.

Gittins, S.P. and J.J. Raemaekers (1980). Siamang, lar and agile gibbons. pp. 63-105. In: Chivers, D.J. (Editor). Malayan forest primate: ten years'field studies in tropical rain forest. Plenum Press, New York. Gross-Custard, J.D., R.I.M. Dunbar and F.P.G. Aldrich-Blake (1972). Survival, mating and rearing strategies in the evolution of primate social structure. Folia Primatologica 17: 1-19.

Klein, L.L. and D.B. Klein (1977). Feeding behaviour of the Colombian spider monkey. pp.153-181. In: Clutton-Brock, T.H. (Editor) Primate Ecology: Studies of Feeding and Ranging Behaviour in Lemurs, Monkeys And Apes. Academic Press, London.

Struhsaker, T.T. and L. Leland (1979). Socioecology of five sympatric monkey species in the Kibale Forest, Uganda, pp. 159-228. In: Rosenblatt, J.S., R.A. Hinde, C. Beer and M.C. Busnel (Editors). Advances in the Study of Behaviour vol. 9. Academic Press, New York. 